\title{
Anterior Interosseous Neuropathy in the Postpartum Period
}

\author{
Lionel Carmant, Martin Veilleux
}

\begin{abstract}
The anterior interosseous neuropathy is a rare focal neuropathy with typical clinical and electromyographic features. Most commonly reported etiologies include lesion of the median nerve following fracture of the radius and ulna, acute or repeated trauma or prolonged pressure on the forearm. In some cases, no predisposing factors can be elicited. Over a one-year period, two young women in their late twenties were evaluated for weakness of the flexor pollicis longus, flexor digitorum profundus of the 2 nd and 3rd fingers, and pronator quadratus muscles that occurred within a month following parturition. Nerve conduction studies and concentric needle electrode examination of the upper extremities performed respectively 3 and 10 months after the onset of symptoms confirmed a severe anterior interosseous neuropathy and excluded more common conditions such as carpal tunnel syndrome, cervical radiculopathy or brachial plexopathy. The prognosis was unfavorable in both cases.
\end{abstract}

RÉSUMÉ: Neuropathie de l'interosseux antérieur dans le post-partum. La neuropathie de l'interosseux antérieur est rarement une neuropathie focale avec des manifestations cliniques et électromyographiques typiques. Les étiologies les plus fréquemment rapportées incluent la lésion du nerf médian suite à une fracture de radius et du cubitus, un traumatisme aigu ou répété, ou une pression prolongée sur l'avant-bras. Dans certains cas, aucun facteur prédisposant ne peut être mis en évidence. Sur une période de un an, deux jeunes femmes dans la vingtaine avancée ont été évaluées pour une faiblesse du long fléchisseur du pouce, de fléchisseur profond des deuxième et troisième doigts et du carré pronateur qui était apparue dans le premier mois du post-partum. Les études de conduction nerveuse et l'examen par électrode-aiguille concentrique des membres supérieurs pratiqué à 3 et 10 mois après le début des symptômes a confirmé la présence d'une neuropathie sévère du nerf interosseux antérieur et a exclu des affections plus fréquentes comme le syndrome du tunnel carpien, la radiculopathie cervicale ou la plexopathie brachiale. Le pronostic a été défavorable dans les deux cas.

Can. J. Neurol. Sci. 1993; 20:56-58

The anterior interosseous neuropathy (AIN) characterized by a isolated weakness of the flexor pollicis longus, pronator quadratus and lateral head of the flexor digitorum profundus muscles ${ }^{1-13}$ was first described by Parsonage and Turner in their series of patients with neuralgic amyotrophy. ${ }^{9}$ In that report, one patient had an isolated AIN and 4 others had an AIN associated with involvement of at least another nerve of the shoulder girdle. In 1952, Kiloh and Nevin ${ }^{3}$ described 2 additional patients with weakness limited to the muscles innervated by the anterior interosseous nerve and considered this focal neuropathy as anatomically distinct. Lesions to this deep pure motor branch of the median nerve are rare and generally reported in patients with occupational or non-occupational trauma. Very few spontaneous cases have been described and, like post-traumatic cases, they usually recover completely and do not require surgical exploration..$^{2-7.11 .12}$
We report two patients with an anterior interosseous neuropathy in the postpartum period who had no other precipitating factors and who recovered poorly.

\section{Case Reports}

Patient 1: Mrs. BBL was a 27-year-old right handed woman who noticed the abrupt onset of pain in the ventral aspect of the right forearm that persisted for a period of 4 weeks, beginning one month after the birth of her first child. However, while the pain was improving, she developed a right hand weakness and started to complain of difficulty with writing. She denied any sensory complaint. The pregnancy had been uneventful except for arterial hypertension and probable ecclampsia in the last trimester that were treated with methyldopa. The delivery was natural and at term, and there were no postpartum complications. Her medical history was non-contributory. She had no history of trauma to the right arm, systemic infection, vaccination, cervical pain, occupational predisposing factors, or family history of peripheral nerve disease.

From the Department of Neurology and Neurosurgery (L.C.) and the Division of Neurology, The Montreal General Hospital (M.V.), McGill University, Montreal

Received June 15, 1992. Accepted September 1, 1992

Presented as an abstract at the 38th Annual Meeting of the American Association of Electrodiagnostic Medicine, Vancouver, Canada, September 2528,1991

Reprint requests to: Dr. Martin Veilleux, Montreal General Hospital, Division of Neurology, 1650 Cedar Avenue, Montreal, Quebec, Canada H3G $1 \mathrm{~A} 4$ 
When seen in the EMG Laboratory 3 months into her illness, the only finding on neurological examination was a weakness of the right hand involving the flexor pollicis longus muscle $4 / 5$, and flexor digitorum profundus of the 2 nd and 3 rd fingers $3 / 5$.

The right median and ulnar, motor and sensory antidromic nerve conduction studies were normal. Concentric needle electrode examination of the right abductor pollicis brevis and pronator muscles was normal. However, needle examination of the right flexor pollicis longus muscle revealed numerous fibrillation and positive wave potentials, a severe loss of motor unit potentials (MUPs) and MUPs of moderately increased amplitude and duration.

In the 6 months following the onset of the symptoms, the right hand weakness slightly improved. However, a year and a half later, she still complains of a pincer-grasp weakness that impairs her writing and fine finger movements of the right hand.

Patient 2: Mrs. LW was a 27-year-old woman with a negative medical history, who developed a left arm pain 2 weeks after giving birth to a child. The pain, which involved the entire left upper extremity to the shoulder, persisted for about 2 weeks and then abated. As the pain subsided, she noticed a weakness of the left hand associated with a subjective tingling sensation in the tip of her left thumb and index fingers. Her pregnancy and delivery were uneventful. She had no prior history of trauma to the left upper extremity, systemic infection, vaccination, or cervical pain. She reported, however, that she had cleaned her swimming pool the week prior to the onset of the symptoms. She had no family history of peripheral nerve disease.

On neurological examination 10 months after the onset of symptoms, the only abnormal finding on neurological examination was a weakness of the left flexor pollicis longus muscle $2 / 5$, and flexor digitorum profundus of the 2 nd and 3 rd fingers $2 / 5$.

The left median and ulnar, motor and palmar sensory nerve conduction studies obtained 10 months after the onset of symptoms were normal. Concentric needle examination of the left abductor pollicis brevis, pronator teres, extensor digitorum communis, first dorsal interosseous, extensor carpi ulnaris, triceps and deltoid muscles was normal. However, needle examination of the lateral head of left flexor digitorum profundus revealed a normal insertional activity but a mild loss of MUPs and MUPs of slightly increased amplitude and duration. In the left flexor pollicis longus muscle, there was a moderate amount of fibrillation and positive wave potentials and no activation of MUPs on voluntary contraction.

Following the electrodiagnostic studies, a surgical exploration of the left median nerve was recommended but the patient declined. She was lost to follow up.

\section{Discussion}

The anterior interosseous neuropathy is a rare but easily recognizable focal motor neuropathy characterized by a weakness of the flexor pollicis longus, pronator quadratus and lateral head of the flexor digitorum profundus muscles. The AIN is responsible for a characteristic pinch attitude with extension of the terminal phalanges of the thumb and index finger and flexion of the metacarpophalangeal joint of the thumb and the proximal interphalangeal joint of the index. The absence of sensory symptoms helps to clinically distinguish the AIN from other types of median nerve injury such as carpal tunnel syndrome and pronator teres syndrome. Nerve conduction studies and concentric needle examination are useful to differentiate the AIN from more common orthopedic conditions such as the rupture of the tendon of the flexor pollicis longus muscle and neurological conditions such as carpal tunnel syndrome, pronator syndrome, cervical radiculopathy and brachial plexopathy. ${ }^{1,4,6,8,10}$ Etiologies for the AIN are numerous but two-thirds of the cases are due to a compression of the nerve by a fibrous band, excessive muscular exercise or pressure on the forearm. ${ }^{4}$ To our knowledge, our patients are the first to be reported in the postpartum period except for a 35-year-old woman reported by Gardner-Thorpe ${ }^{2}$ who thought her symptoms were due to her lifting a baby's carrycot. Unfortunately, he did not provide further information about the time of onset of symptoms following parturition.

The pathogenesis of this focal neuropathy and its link to the postpartum period remains unclear. It is unlikely that this focal nerve injury results from pressure or repeated trauma to the anterior interosseous nerve from carrying a baby mostly in view of its very rare occurrence in postpartum women. One is much more tempted to relate the AIN in the postpartum period to a limited form of brachial plexus neuropathy. First, as reported by Parsonage and Turner ${ }^{9}$ in patients with idiopathic brachial plexus neuropathy, our patients presented initially with arm pain and then developed a weakness in the hand. Second, these authors also described patients with isolated AIN and patients in the postpartum period who had involvement of 2 or more nerves in the upper extremities including the anterior interosseous nerve. Our second case described a severe diffuse pain in the left arm associated with sensory symptoms in the thumb and index fingers early in the course of the illness. Therefore, one wonders whether she might have had a proximal injury to median nerve fascicles that supply the more distally localized anterior interosseous nerve, or a limited involvement of the lower brachial plexus. However, in the latter, a more diffuse involvement of the brachial plexus was ruled out by extensive concentric needle examination.

The prognosis in AIN seems to be very variable, particularly in the patients with no obvious cause $e^{4,8.12}$ but most patients with a spontaneous AIN improve moderately or recover. ${ }^{5,8}$ Conservative treatment was recommended in our first patient because of the good prognosis usually associated with idiopathic brachial plexopathy. However, as suggested by Spinner, ${ }^{12}$ a more aggressive treatment with surgical exploration after a 12 week period could be considered in some patients with dismal prognosis. In fact, a possible entrapment of the fascicles of the anterior interosseous nerve by the pronator teres or flexor digitorum sublimis muscles, lacertus fibrosus aponeurosis, or fibrous bands is reported in cases of idiopathic AIN and can be excluded only by surgery. $4,12,14$

\section{REFERENCES}

1. Dunne JW, Prentice DA, Stewart-Wynne EG. Bilateral anterior interosseous nerve syndromes associated with cytomegalovirus infection. Muscle Nerve 1987; 10: 446-448.

2. Gardner-Thorpe C. Anterior interosseous nerve palsy: spontaneous recovery in two patients. J Neurol 1976; 213:347-352.

3. Kiloh L, Nevin S. Isolated neuritis of the anterior interosseous nerve. $\mathrm{Br}$ Med J 1952; 1: 850-851.

4. Lake PA. Anterior interosseous nerve syndrome. J Neurosurg 1974; 41: 306-309.

5. Miller-Breslow A, Terrono A, Millender LH. Nonoperative treatment of anterior interosseous nerve paralysis. J Hand Surg 1990; 15A: 493-496.

6. Nakano KK, Lundergan C, Okihiro MM. Anterior interosseous nerve syndromes: diagnostic methods and alternative treatments. Arch Neurol 1977; 34: 477-480.

7. Neundorfer B, Kroger M. The anterior interosseous nerve syndrome. J Neurol 1976; 213: 347-352.

8. O'Brien MD, Upton ARM. Anterior interosseous nerve syndrome: a case report with neurophysiological investigation. J Neurol Neurosurg Psychiatry 1972; 35: 531-536.

9. Parsonage MJ, Turner JWA. Neuralgic amyotrophy: the shouldergirdle syndrome. Lancet 1948; i: 973-978.

10. Seror $P$. Le syndrome du nerf interosseux antérieur. Charactéristiques electromyographiques $(2 \mathrm{cas})$ et revue de la 
littérature (62 cas). Rev EEG Neurophysiol Clin 1986; 16: 153163.

11. Smith BH, Herbst BA. Anterior interosseous nerve palsy. Arch Neurol 1974; 30: 330-331.

12. Spinner $M$. The anterior interosseous nerve syndrome. J Bone Joint Surg 1970; 52A: 84-94.
13. Sunderland $\mathrm{S}$. The median nerve. Anatomical and physiological features. In: Eds Nerves and Nerve Injuries (2nd ed). Edinburgh: Churchill Livingstone, 1978: 656-690.

14. Wertsch JJ, Sanger JR, Matloub HS. Pseudo-anterior interosseous nerve syndrome. Muscle Nerve 1985; 8: 68-70. 